\title{
AMS Dating of Early Shellmounds of the Southeastern Brazilian Coast
}

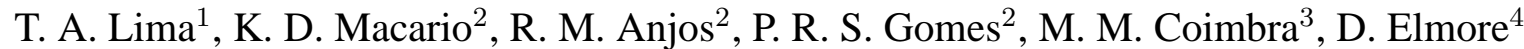 \\ ${ }^{1}$ Departamento de Antropologia, Museu Nacional, Universidade Federal do Rio de Janeiro, \\ Quinta da Boa Vista s/nº, São Cristóvão, CEP 20940-040, Rio de Janeiro, RJ, Brazil \\ ${ }^{2}$ Instituto de Física, Universidade Federal Fluminense, \\ Av. Litorânea s/n, Gragoatá, Niterói, RJ, Brazil, CEP 24210-340 \\ ${ }^{3}$ Departamento de Física - CCE, Universidade Estadual de Londrina, \\ Caixa Postal 6001, CEP 86051-990, Londrina, PR, Brazil, \\ ${ }^{4}$ Purdue Rare Isotope Measurement Laboratory, Purdue University, \\ 1396 Physics Building, West Lafayette, IN, USA 47907-1396
}

Received on 30 October, 2002

\begin{abstract}
This paper discusses the chronology of prehistoric settlements of the central-south Brazilian coast. A charcoal sample from a coastal shellmound of Rio de Janeiro State was dated by ${ }^{14} \mathrm{C}$-AMS to $7,860 \pm 80$ years BP as part of an interdisciplinary project between physicists and archaeologists. This is an unexpected result that reinforces two similar previous early dates for the same region, which were questioned by Brazilian archaeologists because they implied in pulling back by some two thousand years the antiquity consensually accepted for the settlement of that region.
\end{abstract}

\section{The use of AMS Technique in Brazil}

This paper is the outcome of an interdisciplinary project that brings together physicists and archaeologists with the aim of providing the entire Brazilian scientific community a sample preparation laboratory dedicated to Accelerator Mass Spectrometry. The AMS technique for radioisotope dating, as a powerful tool used by several areas to date milligram samples of various kinds, is today only offered by foreign labs.

The Brazilian AMS Program [1] started in 1993 at Universidade de São Paulo (USP), was dedicated to mount an exclusive setup in one of the beam lines of the Pelletron 8UD for AMS dating [2,3,4], and has been developing since then. Presently this program is focused on the Sample Preparation Lab in implantation at the Physics Institute of Universidade Federal Fluminense (UFF).

With the aim of acquiring experience in sample preparation techniques and, at the same time, providing free radiocarbon dating for geology and archeology groups, we have prepared 27 carbon samples, including bone, charcoal, shell and ceramic, at the Purdue Rare Isotope Measurement Laboratory (PRIME Lab), Indiana, USA.

In this specific paper we present the procedures and results for four charcoal samples collected from four different shellmounds in the Ribeira Bay, in Angra dos Reis, Rio de Janeiro $\left(22^{\circ} 55^{\prime} 48^{\prime \prime} \mathrm{S} 44^{\circ} 20^{\prime} 48^{\prime \prime} \mathrm{W}\right)$. The sites integrate a group of seven shellmounds built very close together in dif- ferent islets of the Ribeira Bay. Those dates were supposed to confirm that the sites were contemporaneous, one of them having its superior level previously dated to $(3,350 \pm 80) \mathrm{BP}$ (WSU 3359) [5].

\section{Chronology of the Brazilian Shell- mounds}

Especially rich in mollusks, crustaceans and fish, the estuarine environments of the Brazilian central-south coast favored the settlement of prehistoric hunters-gatherers $[6,7]$ probably coming from the inland highlands. By the time they reached the coast they became fishers and shellfish gatherers, given that shellfish is one of the most plentiful and easily caught marine resources in such environments. Among their food resources, shellfish was of major importance; it was actually the proximity to mollusk beds that determined their settlement choices. Through the intentional accumulation of food refuse (primarily mollusks and animal bones) and sediments, they built mounds where we now find evidence of their daily life and funeral rituals.

In the southern Brazilian coast there is a high density of shellmounds, which are sometimes as high as thirty meters. They are found from the northern coast of Rio Grande do Sul $\left(51^{\circ} \mathrm{W}, 30^{\circ} \mathrm{S}\right)$ to the state of Bahia $\left(38^{\circ} \mathrm{W}, 15^{\circ} \mathrm{S}\right)$, and they are more conspicuous and densely concentrated in 
the state of Santa Catarina $\left(47^{\circ} \mathrm{W}, 28^{\circ} \mathrm{S}\right)$. As one moves north from Santa Catarina through the states of Paraná, São Paulo, Rio de Janeiro and Espírito Santo, they thin out progressively and disappear, since Brazil's straight northeastern coast does not count with the lagoonal areas with environmental conditions that favor this way of life.

These shellmounds are dated in general between 6,000 and 2,000 BP. The material culture recovered in these sites consists essentially of artifacts made from shells and bones of bird, fish, sea and land mammals, including projectile points, ornaments, and other tools and weapons. Thanks to the abundance of fish and shellfish in the estuarine environment substantial demographic growth was possible. With an abundant food supply all year round, fisher-gatheres enjoyed the benefits of an extremely favorable interaction of elements within their subsistence system. As time went on, population growth decreased the distance between settlements, resulting in a high density of sites within these circumscribed lagoonal areas.

The radiocarbon dating of shellmounds is crucial for the understanding of the rise, maintenance, and collapse of these socio-cultural systems that flourished in the course of at least four thousand years or even more, until the beginning of the Christian era, when their occupational evidences disappear. By this time, the bold and well-succeeded inland horticulturalists arrived at the coast. Able to produce their own food, hence more powerful economically, with a different and somewhat more complex social organization, more advanced from a technological standpoint, and more expres- sive numerically, they ended up determining the absorption or extinction of the fisher-gatherers.

There are currently some 290 radiocarbon dates available for Brazilian shellmounds, which attest to the initial occupation of the coast at around 6,500 BP [7]. The distribution of the frequency of such dates shows that these cultures seem to have reached their peak between 5,000 and 3,000 years BP.

\section{Sample Collection, Preparation and Dating}

The samples were collected from four shellmounds very close to each other in four small islands of the Ribeira Bay, in Angra dos Reis, Rio de Janeiro, namely Algodão, Caieira, Peri and Major (see map in Fig. 1).

The Shellmound of Algodão, located in a small island of same name, presents two distinct stratigraphic levels: the inferior, where an abundant capture of mollusks took place; and the superior, where there was a clear increase in fishing as a means of compensating the smaller availability of mollusks. The superior level, dated some fifteen years ago to $(3,350 \pm 80) \mathrm{BP}$ (WSU 3359) [5], was supposed to be contemporaneous to the other shellmounds of the area. The sample, now dated through AMS, was collected from the inferior level at $60 \mathrm{~cm}$ depth and should represent a different and older occupation.

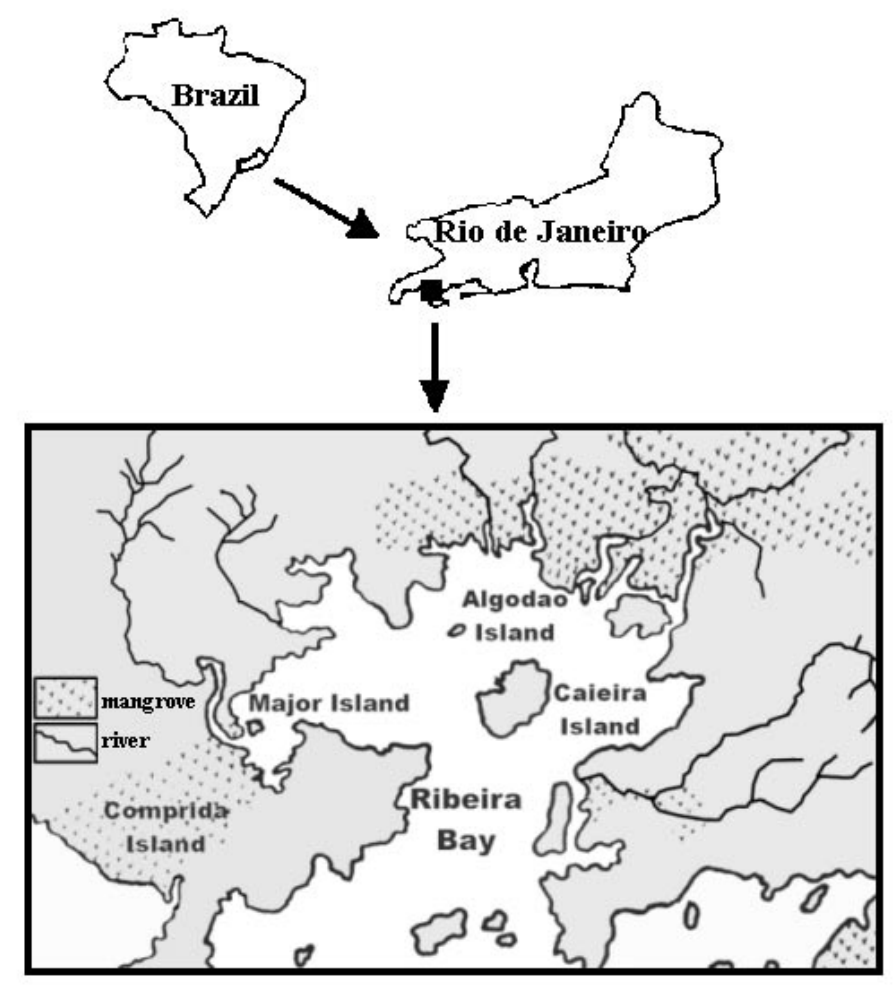

Figure 1. Map of the Ribeira Bay, Rio de Janeiro. 
The Caieira sample was collected at a depth of $40 \mathrm{~cm}$ from the top of the shellmound in Caieira Island and the Peri sample at a depth of $1 \mathrm{~m}$ in Comprida Island. The Major sample comes from a depth of $40 \mathrm{~cm}$ in the Major Island.

All the samples were collected between 1985 and 1987, with metal forceps during the excavation and packed in aluminum foil, stored in plastic bags until they were sent to PRIME Lab for preparation.

The usual chemical pre-treatment for organic samples was performed. The samples were reduced to 1 to $2 \mathrm{~mm}$ thickness and treated with hydrochloric acid to remove the inorganic fraction. A base treatment, with sodium hydroxide, was made in order to remove the fulvic and humic fractions. Finally, another acid treatment removed the inorganic carbon that could have been incorporated to the samples during the base treatment. The samples were then dried and combusted in evacuated quartz tubes with a silver foil and Copper Oxide, at $900^{\circ} \mathrm{C}$. The gas samples were processed in a graphitization line where water and other gases were discarded so that the $\mathrm{CO}_{2}$ could be transferred to quartz tubes with zinc and iron. The tubes were sealed and heated at $700^{\circ} \mathrm{C}$ for two periods of 10 hours for the graphitization to be complete. The graphite was finally pressed into a copper cathode and measured in the accelerator.

The 7.5 MV FN Tandem accelerator of the PRIME Lab was used for the measurements. The terminal voltage used was $4 \mathrm{MV}$, and ${ }^{13,14} \mathrm{C}$ beams, with charge state $3+$, were selected by the high-energy magnetic analyzer and detected.

The conventional radiocarbon age was calculated as in Donahue et al. [8] and the oxalic acid standard used was the NBS SRM 4990 C. The calibration was made using the computer program Ox Cal 3.5[9] based on the data from Stuiver et al.[10].

\section{Results and Discussion}

For the Peri (PLID T00-0678) and Caieira (PLID T000680) samples the results were respectively $(1420 \pm 80) \mathrm{BP}$ or cal AD 530 - $890(2 \sigma$, what means a $95.4 \%$ confidence interval) and (1520 \pm 80$) \mathrm{BP}$ or cal AD $400-690(2 \sigma)$. On the one hand, these results corroborate the idea of contemporaneousness only between those two sites, but on the other, it distances them from the chronology obtained for Algodão's superior level, which is much older.

The sample from the Major shellmound (PLID T000679) was dated to $(190 \pm 80) \mathrm{BP}$ or cal AD $1630-1950(2$ $\sigma)$. This date was considered too late, and seems to correspond to the colonial occupation found in the superficial layer of the site.

The inferior level of Algodão (PLID T00-0677) was dated to $(7860 \pm 80)$ BP or cal BC 7050-6450 (2 $\sigma)$. Such an early date would be considered wrong if there had not been three other single dates, out of the expected range of occurrence of shellmounds and so remarkably contemporaneous $[11,12]$.

Three very early radiocarbon dates were obtained decades ago for two different shellmounds; nevertheless, since they were considerably out of the average age range for these sites, they have been harshly contested by the professional community. In 1956, Laming and Emperaire [13] obtained two dates of $7,803 \pm 1,300 \mathrm{BP}$ and $7,327 \pm 1300 \mathrm{BP}$ in Gif-sur-Yvette, France, for the Shellmound of Maratuá, located in the region of Santos, São Paulo. The dates were refuted due to the reason exposed above [14]. In 1981, Kneip [15] obtained a second similar date: 7,958 \pm 224 BP (SPC 207), at the Shellmound of Camboinhas, in Rio de Janeiro (22 $58^{\circ}$ 'S $\left.43^{\circ} 3^{\prime} \mathrm{W}\right)$. Such a dating was also contested for the same reasons and with the supposition, that turned out to be mistaken [16], that the sand strips over which the shellmounds stood were more recent and would have been formed after the presumed date of the site. Until the present, both dates were seen with a strong distrust.

Those sites together with the Algodão have geographical proximity, in the axis Rio de Janeiro / São Paulo of the southeast region, but they are very distant of the nuclear area of Santa Catarina.

\section{Conclusions}

Up until now, it would be admissible to assume that the oldest dates would be found among the huge shellmounds of Santa Catarina. Nevertheless, it is surprising that the oldest dates appear in Rio de Janeiro and São Paulo. This demonstrates that the initial settlements occurred in an area that does not coincide with the one in which those cultures reached their highest degree of expression.

The origin and routes through which the huntergatherers reached the coast and became its oldest fishergatherers are still questions to be answered, since there is no evidence of hunter-gatherers in the highland region of Rio de Janeiro. From the present result we could cogitate that those fisher-gatherers could have originated in the São Paulo plateau, not far from the site of the Algodão shellmound. We consider that the Ribeira Valley, in São Paulo, is one of the few possible routes of communication between the coast and the countryside in the extensive barrier constituted by the Serra do Mar mountainous range. This hypothesis is reinforced by the existence of sites with fluvial mollusks along the Ribeira River course, one of which dated 9,000 BP [17].

Therefore, the present result compels us to consider the two previously questioned dates, pulling back the traditionally accepted chronology for the settling of the coast by at least two thousand years.

\section{Acknowledgement}

The authors would like to thank the Brazilian funding agencies $\mathrm{CNPq}$, FAPERJ and CAPES, for their financial support. We would like to thank the staff of the PRIME Lab, especially Dr. David Elmore, Ken Mueller, Mary Ann Rounds, Pankaj Sharma and Linda Paquay, for their hospitality with K.D. Macario during the period of sample preparation. We would also like to thank Rosana Najjar 
from IPHAN-Institute for National Historical and Artistic Heritage-for having introduced physicists and archeologists, making it possible for this invaluable interchange to happen.

\section{References}

[1] C. Tenreiro, R.M. Anjos, J.C. Acquadro, G. Kremer, G. Ramirez, Nucl. Instr. Meth. in Phys. Res. B92, 89 (1994).

[2] G.M. Santos, J.C. Acquadro, R.M. Anjos, P.R.S. Gomes, C. Tenreiro, R. Liguori Neto, M.M. Coimbra, C.R. Appoloni, A.M.M. Maciel, N.H. Medina, M.A. Rizzuto, and N. Carlin Filho, Nucl. Instr. Meth. in Phys. Res. B123, 34 (1997).

[3] P.R.S. Gomes, R.M. Anjos, J.C. Acquadro, G.M. Santos, K.D. Macario, R. Liguori Neto, N. Added, M.M. Coimbra, C.R. Appoloni, N.V. Faria de Castro, S.D. Magalhães, R. Donangelo, Nucl. Instr. Meth. in Phys. Res. B172, 82 (2000).

[4] P.R.S. Gomes, R.M. Anjos, J.C. Acquadro, G.M. Santos, K.D. Macario, R. Liguori Neto, N. Added, R.C. Cordeiro, B. Turcq, A. Sifeddine, M.M. Coimbra, C.R. Appoloni, M. di Tada, R.G. Cresswell, and L.K. Fifield, Heavy Íon Physics 11, 485 (2000).

[5] T.A. Lima. PhD Tesis, Universidade de São Paulo, Brasil. (1991).

[6] T.A. Lima. Abstracts of the 62nd Annual Meeting Society for American Archaeology, Nashville, Tennessee. 135-136 (1997).
[7] T.A. Lima. Revista da Universidade de São Paulo, Brasil. 2, 270 (2000).

[8] D.J. Donahue, T.W. Linick, and A.J.T. Jull, Radiocarbon. 32(2), 135 (1990).

[9] OxCal v3.5 Ramsey B. (2000).

[10] M. Stuiver, P.J. Reimer, E. Bard, J.W. Beck, G.S. Burr, K.A. Hughen, B. Kromer, G. McCormac, J. van der Plicht. and M. Spurk Radiocarbon 40(3) 1041-1083(1998)

[11] T.A. Lima, K.D. Macario, R.M. Anjos, P.R.S. Gomes, M.M. Coimbra, and D. Elmore. Submitted to Nucl. Instr. Meth. in Phys. Res. (2002).

[12] T.A. Lima, K.D. Macario, R.M. Anjos, P.R.S. Gomes, M.M. Coimbra, D. Elmore. Submitted to Radiocarbon (2002).

[13] J. Emperaire, A. Laming. Journal de la Societé des Americanistes, Paris. 45, 5-163 (1956).

[14] C.R. Garcia, Revista de Pré-História 1(1), 15 (1979).

[15] L.M. Kneip, L. Pallestrini, J.L. Morais, and F.L.S. Cunha, Anais da Academia Brasileira de Ciências. Rio de Janeiro: Academia Brasileira de Ciências. 53, 339 (1981).

[16] D. Muehe, L.M. Kneip. Documento de Trabalho ${ }^{o}$ 3, Série Arqueologia, Museu Nacional / UFRJ, Brasil. (1995)

[17] P.A.D. Blasis, In: Resumos do XI Congresso da Sociedade de Arqueologia Brasileira. 43 (2001). 